\title{
Incidental findings in CT imaging of coronary artery bypass grafts: results from a Canadian multicenter prospective cohort
}

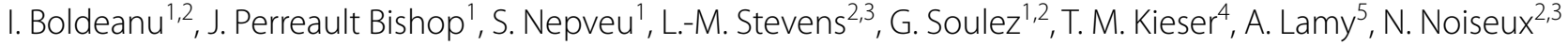 \\ and C. Chartrand-Lefebvre ${ }^{1,2^{*}}$
}

\begin{abstract}
Objective: To assess the prevalence and clinical significance of incidental findings identified during computed tomography imaging of coronary artery bypass grafts.

Results: This prospective study includes 144 patients undergoing coronary graft patency assessment using computed tomography. Incidental findings were classified as significant if they were considered to need an immediate action or treatment, short-term work-up or follow-up, or minor. A total of 211 incidental findings were present in 109 (75.7\%) patients. Seventy-one incidental findings (33.6\%) were cardiac and 140 (66.4\%) were extracardiac. Most common cardiac incidental findings were atrial dilatation [39 patients, 48 incidental findings (67.6\%)] and aortic valve calcifications (7 patients, 9.9\%). Among the 140 extracardiac incidental findings, the most common were lung nodules (51 patients, 54 nodules, 38.6\%), and emphysema (21 patients, 15\%). Thirty-six (25.7\%) extracardiac incidental findings were significant and notably, 23 (63.9\%) were lung nodules. Follow-up was recommended in 37 cases, among which all patients with significant lung nodules (23 patients, 62.2\%). In conclusion, most common computed tomography incidental findings in patients with coronary grafts were lung nodules and emphysema.
\end{abstract}

Keywords: Incidental findings, Cardiac computed tomography, Lung, Coronary bypass graft, Lung nodule, Emphysema

\section{Introduction}

Heart disease remains the main cause of hospitalization and death in industrialized countries, with a significant health care burden [1]. In specific cases, coronary artery bypass graft surgery (CABG) is the therapeutic approach of choice in order to restore adequate blood flow to an ischemic heart and prevent further cardiovascular complications [2]. It is estimated 300,000 CABG surgeries are performed per year in the United States alone [3]. CABG can be performed either using cardiopulmonary bypass (on-pump) [4-6] or off-pump techniques [2,7].

In contrast to other cardiac imaging modalities such as echocardiography, nuclear medicine studies or even

\footnotetext{
*Correspondence: chartrandlef@videotron.ca

${ }^{1}$ Department of Radiology, Centre Hospitalier de I'Université de Montréal (CHUM), 1051 Sanguinet Street, Montreal, QC H2X 0C1, Canada

Full list of author information is available at the end of the article
}

cardiac magnetic resonance, cardiac computed tomography $(\mathrm{CT})$ allows to visualize the surrounding lungs, mediastinum, pleura and upper abdominal cavity in addition to the heart. The assessability of extracardiac anatomy and incidental findings (IF) gives the opportunity for alternative diagnoses to the patient's symptoms, or for the detection of lesions otherwise silent at the time of the examination $[8,9]$. IF may include findings from benign and nonsignificant incidentals such as benign chest granulomatous disease to malignant pulmonary nodules. The overall prevalence of extracardiac findings is high. A meta-analysis reported a pooled prevalence of $44 \%$ in patients undergoing cardiac CT examinations, most of which were performed for coronary calcium scoring or coronary CT angiography [9].

However, prevalence of IF may vary according to the specific indication or population in which cardiac CT is 
used. Moreover, CT scanning for coronary calcium scoring or coronary $\mathrm{CT}$ angiography is limited to the heart and involves limited portions of the extracardiac anatomy. In contrast, $\mathrm{CT}$ acquisition performed for CABG evaluation involves more lung volume to be assessable, since scanning will cover from the length of the mammary arteries as well as the heart. In addition, some individuals undergoing calcium scoring or coronary $\mathrm{CT}$ angiography are only at low risk for lung cancer. Most patients with CABG, on the other hand, are often current or former smokers at increased risk for IF, especially pulmonary nodules.

This study includes 144 consecutive CABG patients undergoing graft patency prospective assessment using $\mathrm{CT}$ angiography at 1-year postoperative follow-up. It aims to assess the prevalence of both benign and significant cardiac and extra-cardiac IF in the specific population of patients with CABG.

\section{Main text \\ Methods \\ Study population}

The CABG Off or On Pump Revascularization Study (CORONARY) is a prospective randomized trial $(\mathrm{N}=4752$ patients) comparing CABG surgery performed on- or off-pump (NCT00463294, registration April 18, 2007) [10]. A secondary study of CORONARY was held in three Canadian centers $(\mathrm{N}=157$ patients) with the objective to evaluate CABG patency after 1-year follow-up using CT [7]. The present study includes the initial 144 patients [122 males, 22 females, median age $69.0(64.0-75.0)$ years] recruited in this secondary study.

\section{CT imaging}

CT acquisition In the three institutions, a total of three scanners were used: a 256-slice CT scanner (Brilliance iCT, Philips Healthcare, Cleveland, OH, USA) in 117 patients (site 1), and two 64-slice scanners (Aquilion64, Toshiba Medical Systems, Tochigi, Japan; and GE LightSpeed VCT; GE Healthcare, USA), in 16 (site 2) and 11 (site 3) patients, respectively. Image acquisition used a matrix of $512 \times 512$ and a field-of-view (FOV) of $250 \mathrm{~mm}$. Scan voltage was $120 \mathrm{kV}$, and gantry speed varied from 270 to $400 \mathrm{~ms}$. Slice thickness was $0.5-0.625 \mathrm{~mm}$. Prospective ECG-gating was used when available, for heart rate $<70 \mathrm{bpm}$; if not, retrospective ECG-gating was used. Scans were performed during shallow inspiration breathhold, with scan range from the clavicles to the lung bases just caudal to the heart in order to visualize the heart as well as the internal mammary arteries. The contrast agent was administered at $5 \mathrm{ml} / \mathrm{s}$.

Image reconstruction and postprocessing Image reconstruction used both standard (smooth) and lung ker- nels. In sites 2 and 3, a larger reconstructed FOV of $320-500 \mathrm{~mm}$ was also used, with lung kernel. At the time of the study, filtered back projection was used for image reconstruction. One observer $(\mathrm{CCL}, 15$-year experience in cardiovascular CT) reviewed all images and performed CABG patency image analysis in a central core lab (site 1).

\section{IF classification}

Incidental findings were recorded prospectively. IF were defined as unexpected observations of potential clinical significance and unrelated to the main purpose of the CORONARY CT angiography secondary study (i.e. graft patency assessment). IF were classified as significant if they were considered to need a clinical action, or minor. If deemed significant, the findings were further described regarding the type of action needed (treatment, work-up or followup) and the time period in which these actions were to be performed. The Fleischner Society pulmonary nodule recommendations were used to evaluate and manage solid and subsolid incidental pulmonary lung nodules [11, 12]. The time periods were categorized as $0-0.9$ month (requiring immediate action), 1-2.9, 3-5.9, 6-9.9 or 9-12 months. Imaging follow-up modalities included CT, magnetic resonance, ultrasonography, or other. The findings were also categorized in respect to their anatomical location, as well as the type of abnormality. Native distal bed coronary artery stenoses were collected in the CORONARY CT angiography study, but however were not considered as incidental in this population of patients with coronary disease.

\section{Statistical analysis}

Data were expressed as median and interquartile range (Q1-Q3) for continuous variables, and as frequencies (percentages) for categorical variables. The MannWhitney $U$ test was used for continuous variables. For categorical variables, the Fisher exact test was used. A two-tailed $p$ value $<0.05$ was considered significant. Statistical analyses were performed using SPSS (version 22, Inc, Chicago, Illinois).

\section{Results}

All CT scans were completed successfully. No scan was excluded from the analysis. Median z-axis scan coverage was $250.0(235.25-272.0) \mathrm{mm}$. See Table 1 for additional scan-related parameters.

\section{Global incidental findings}

Among the 144 patients, a total of 211 IF were present in $109(75.7 \%)$ patients. Thirty-five patients $(24.3 \%)$ presented no IF. Among the 211 IF recorded, 71 (33.6\%) were cardiac IF in 52 patients and $140(66.4 \%)$ were extracardiac IF in 87 patients (some patients presented both) (Table 2). 
Table 1 Patient characteristics and scan-related parameters

\begin{tabular}{|c|c|}
\hline \multicolumn{2}{|l|}{ Patient characteristics ( $n=144$ patients) } \\
\hline Men/women & $122 / 22$ \\
\hline Age (years) [median (Q1-Q3)] & $69.0(64.0-75.0)$ \\
\hline Presence of IF $(n, \%)$ & $109(75.7 \%)$ \\
\hline BMI $\left(\mathrm{kg} / \mathrm{m}^{2}\right)$ [median (Q1-Q3)] & $27.40(25.48-30.42)$ \\
\hline Smoker $^{\mathrm{a}}(\mathrm{n}, \%)$ & 105 (72.9\%) \\
\hline Hypertension (n, \%) & $126(87.5 \%)$ \\
\hline Diabetes (n, \%) & $47(32.6 \%)$ \\
\hline Renal insufficiency (n, \%) & $11(7.6 \%)$ \\
\hline $\mathrm{CHF}(\mathrm{n}, \%)$ & $5(3.5 \%)$ \\
\hline \multicolumn{2}{|l|}{ EuroScore } \\
\hline $1(n, \%)$ & $17(11.8 \%)$ \\
\hline $2(n, \%)$ & $27(18.8 \%)$ \\
\hline $3(n, \%)$ & $45(31.3 \%)$ \\
\hline $4(n, \%)$ & $31(21.5 \%)$ \\
\hline $5(n, \%)$ & $19(13.2 \%)$ \\
\hline $6(n, \%)$ & $4(2.8 \%)$ \\
\hline $7(n, \%)$ & $0(0.0 \%)$ \\
\hline $8(n, \%)$ & $1(0.7 \%)$ \\
\hline \multicolumn{2}{|l|}{ Scan-related parameters } \\
\hline $\begin{array}{l}\text { Mean heart rate during scan (bpm) [median } \\
(\mathrm{Q} 1-\mathrm{Q} 3)]\end{array}$ & $58.0(53.0-64.0)$ \\
\hline Prescan betablocker administration $(\mathrm{n}, \%)$ & $65(45.1 \%)$ \\
\hline Prescan nitroglycerin administration $(n, \%)$ & $137(95.1 \%)$ \\
\hline Contrast agent (ml) [median (Q1-Q3)] & $102.0(100.0-105.75)$ \\
\hline Scan coverage (mm) [median (Q1-Q3)] & $250.0(235.25-272.0)$ \\
\hline DLP (mGy-cm) [median (Q1-Q3)] & $683.0(469.0-897.0)$ \\
\hline Effective dose $^{\mathrm{b}}$ (mSv) [median (Q1-Q3)] & $9.6(6.6-12.6)$ \\
\hline ECG gating (prospective/retrospective) & $134 / 10$ \\
\hline
\end{tabular}

$B M I$ Body mass index, bpm beats per minute, CHF congestive heart failure, EuroSCORE European System for Cardiac Operative Risk Evaluation, IF incidental findings, DLP dose-length product for $C T$ angiography

${ }^{a}$ Current and former smokers were considered as smokers

${ }^{b}$ The effective radiation dose was estimated by the product of the DLP and a conversion coefficient for the thorax $\left(\mathrm{k}=0.014 \mathrm{mSv} \mathrm{mGy}^{-1} \mathrm{~cm}^{-1}\right)$

Among cardiac findings, the most common findings were left or right atrial dilatation (or both) [39 patients, total of 48 IF (67.6\% of cardiac IF)] and aortic valve calcifications (7 patients, $9.9 \%$ of cardiac IF) (Table 2). Other cardiac findings included left ventricular hypertrophy, atrial septal aneurysm, pericardial effusion, left atrial thrombus and intra-atrial shunt. Additional file 1 describes the case of the intra-atrial shunt. A case of lipomatous metaplasia of the left ventricular wall suggestive of a chronic myocardial infarction is shown in Additional file 2. A cardiac ultrasound was recommended for the case of left ventricular hypertrophy. Other findings were already known by the treating team or were the subject of contemporary work-up.
Table 2 Prevalence of incidental cardiac and extracardiac findings

\begin{tabular}{|c|c|c|c|c|}
\hline & $\begin{array}{l}\text { Total } \\
\text { IF }\end{array}$ & $\begin{array}{l}\% \text { of cardiac or } \\
\text { extracardiac IF }\end{array}$ & $\begin{array}{l}\% \text { of all } \\
\text { IF }\end{array}$ & $\begin{array}{l}\text { Significant } \\
\text { IF }\end{array}$ \\
\hline \multicolumn{5}{|l|}{ Incidental cardiac findings } \\
\hline Left atrial dilatation & 34 & 47.9 & 16.1 & \\
\hline Right atrial dilatation & 14 & 19.7 & 6.6 & \\
\hline $\begin{array}{l}\text { Aortic valve calcifica- } \\
\text { tions }\end{array}$ & 7 & 9.9 & 3.3 & \\
\hline $\begin{array}{l}\text { Lipomatous metapla- } \\
\text { sia (chronic myocar- } \\
\text { dial infarction) }\end{array}$ & 3 & 4.2 & 1.4 & \\
\hline Pericardial effusion & 3 & 4.2 & 1.4 & \\
\hline $\begin{array}{l}\text { Left ventricular hyper- } \\
\text { trophy }\end{array}$ & 2 & 2.3 & 1.0 & 1 \\
\hline Atrial septal aneurysm & 1 & 1.4 & 0.5 & \\
\hline Left atrial thrombus & 1 & 1.4 & 0.5 & \\
\hline Other & 6 & 8.5 & 2.8 & \\
\hline Total & 71 & 100.0 & 33.6 & 1 \\
\hline \multicolumn{5}{|c|}{ Incidental extracardiac findings } \\
\hline Pulmonary nodules & 54 & 38.6 & 25.6 & 23 \\
\hline Emphysema & 21 & 15.0 & 10.0 & \\
\hline $\begin{array}{l}\text { Pleural effusion/thick- } \\
\text { ening }\end{array}$ & 6 & 4.2 & 2.8 & \\
\hline $\begin{array}{l}\text { Thoracic aorta dilata- } \\
\text { tion }\end{array}$ & 5 & 3.6 & 2.4 & \\
\hline $\begin{array}{l}\text { Enlarged mediastinal } \\
\text { lymph nodes }\end{array}$ & 4 & 2.9 & 1.9 & 3 \\
\hline $\begin{array}{l}\text { Subclavian artery } \\
\text { stenosis }\end{array}$ & 4 & 2,9 & 1.9 & \\
\hline $\begin{array}{l}\text { Main pulmonary } \\
\text { artery dilatation }\end{array}$ & 2 & 1.4 & 1.0 & \\
\hline $\begin{array}{l}\text { Brachiocephalic artery } \\
\text { stenosis }\end{array}$ & 1 & 0.7 & 0.5 & \\
\hline Pulmonary infiltrates & 1 & 0.7 & 0.5 & 1 \\
\hline Hiatal hernia & 17 & 12.1 & 8.1 & \\
\hline Hepatic lesions & 10 & 7.1 & 4.7 & 6 \\
\hline $\begin{array}{l}\text { Abdominal aorta } \\
\text { aneurysm }\end{array}$ & 1 & 0.7 & 0.5 & \\
\hline $\begin{array}{l}\text { Adrenal gland } \\
\text { adenoma }\end{array}$ & 1 & 0.7 & 0.5 & \\
\hline Thyroid nodules & 7 & 5.0 & 3.3 & 3 \\
\hline Breast abnormalities & 2 & 1.4 & 1.0 & \\
\hline Other & 4 & 2.9 & 1.9 & \\
\hline Total & 140 & 100 & 66.4 & 36 \\
\hline
\end{tabular}

A total of 140 extracardiac IF were found in 87 (60.4\%) of our 144 patients. The most common were pulmonary nodules [51 patients; 54 nodules (38.6\% of extracardiac IF)], followed by emphysema (21 patients, $15.0 \%$ ). Thirty-six $(25.7 \%)$ extracardiac IF were categorized as significant. Notably, near two-thirds $(23,63.9 \%)$ of significant extracardiac IF were pulmonary nodules. Median size was $5.65(4.00-7.75) \mathrm{mm}$; range was $3-11 \mathrm{~mm})$. 
CT follow up was recommended for the 23 significant pulmonary nodules. Extrathoracic IF involved the abdominal (29 cases, $20.7 \%$ of all extracardiac IF), cervical (7 cases, $5.0 \%)$ and mammary (2 cases, $1.4 \%$ ) regions (Table 2). Recommendations for clinically significant extracardiac findings, other than pulmonary nodules, were abdominal, cervical or breast ultrasonography.

\section{Significant incidental findings}

Thirty-seven significant incidental findings occurred in $36(25 \%)$ patients. Pulmonary nodules (23 patients, $62.2 \%$ of significant IF) and hepatic lesions (6 patients, 16.2\%) were the most common. Additional files 3 and 4 describe cases of incidental lung and hepatic findings. Cases of thyroid nodule (3 patients, $8.1 \%$ ) and enlarged mediastinal lymph nodes (3 patients, 8.1\%) were also observed, as well as a single case of left ventricular hypertrophy (2.7\%) and one of pulmonary infiltrate (2.7\%). Most follow-up recommendations involved CT (73\%). Ultrasonography was suggested for all other cases (23\%). Time periods for follow-up are described in Table 3.

\section{Comparison between patients with and without IF}

Patients of both groups had comparable baseline demographics and selected clinical variables, except for a significantly lower prevalence of congestive heart failure in patients who presented incidental findings $(\mathrm{p}=0.041)$. A description of the patient characteristics by incidental finding status is provided in Additional file 5. Among patients with lung nodules versus without, proportion of current or former smokers were $60.9 \%$ (25/41) and $77.6 \%$

\section{Table 3 Prevalence of incidental findings requiring action according to type of work-up and time period suggested for follow-up ( $n=37$ cases of IF)}

\begin{tabular}{lc}
\hline Type of IF $(\mathrm{n}, \%)$ & \\
Pulmonary nodule & $23(62.2)$ \\
Pulmonary infiltrate & $1(2.7)$ \\
Enlarged mediastinal lymph nodes & $3(8.1)$ \\
Left ventricular hypertrophy & $1(2.7)$ \\
Thyroid nodule & $3(8.1)$ \\
Hepatic lesion & $6(16.2)$ \\
Type of recommended modality for follow-up (n, \%) & \\
Computed tomography & $27(73.0)$ \\
Ultrasonography & $10(27.0)$ \\
Time frame of recommended follow-up (n, \%), months & \\
0-0.9 & $3(8.1)$ \\
0-2.9 & $11(29.7)$ \\
3-5.9 & $14(37.8)$ \\
$6-8.9$ & $3(8.1)$ \\
9-11.9 & $6(16.2)$ \\
\hline
\end{tabular}

$(80 / 103)$, respectively $(\mathrm{p}=0.060)$. Among patients with significant lung nodules versus without any nodules, the proportions of current or former smokers were $70.0 \%$ $(16 / 23)$ and $76.8 \%(73 / 95)$, respectively $(\mathrm{p}=0.590)$.

\section{Discussion}

This is a multicenter study involving 144 CABG patients, with prospective assessment of cardiac CT scans for minor or significant IF. A total of 211 IF were found in 109 (75.7\%) patients. Most IF (66.4\%) were extracardiac IF. Pulmonary nodules accounted for more than half of the significant IF. Hepatic lesions were the second most frequent significant IF.

In a recent meta-analysis, the pooled prevalence of cardiac CT patients with at least one extracardiac IF was $44 \%$ [9]. Prevalence in the primary studies of this meta-analysis showed a high variability, ranging from $14.8 \%$ [13] to $79.4 \%[9,14]$. This variability is probably due to the different patient populations studied. Of note, extracardiac IF in our population of CABG patients had a prevalence of $60.4 \%$. Study design, CT protocol, patient characteristics and level of attention to incidental findings may also explain this variability $[9,15]$. Another cause to this heterogeneity is the interobserver discordance as to the presence or significance of IF [16].

Pulmonary nodules were the most frequent significant IF in our study, accounting for $62.2 \%$ of all significant IF, and occurring in 23 (16.0\%) of patients. Previous studies reported that prevalence of significant pulmonary nodules in cardiac CT were 0.9\% [13] to $16.5 \%$ [17]. Excluding electron-beam CT from its dataset, the calculated weighted prevalence of significant pulmonary nodules in Earls' review paper is 3.8\% [15]. Another meta-analysis reported pooled prevalences of $16 \%$ for significant IF and of $0.7 \%$ for incidental cancer, of which most were lung cancer [9]. In view of these rates of significant IF and incidental cancers, as well as of results of lung cancer screening trials with CT showing reduction of mortality due to lung cancer $[18,19]$, many authors advocate that all images from cardiac $\mathrm{CT}$ should be reviewed by an expert thoracic $\mathrm{CT}$ imager.

Only two former studies assessed IF in the specific population of CABG patients. A retrospective study [20] of 259 patients assessed with 16-slice CT during the immediate postoperative period, of which 40 patients were also assessed prospectively after a mean follow-up of 12.7 months. $13.1 \%$ of their patients had a significant noncardiac IF. Especially, prevalence of significant pulmonary nodules was $3.5 \%$. Another retrospective study [21] included 223 patients with CABG, assessed with 64-slice CT outside the postoperative period. The prevalence of pulmonary nodules was $10.8 \%$. In comparison, 
our study had a prospective design, with prevalence of significant pulmonary nodules of $16 \%$. Description of studies assessing incidental findings in cardiac CT is available in Additional file 6.

In conclusion, our multicenter prospective study involving 144 CABG patients assessed with CT shows a $25 \%$ prevalence of significant extracardiac IF, most of which were pulmonary nodules. With these results in mind, as well as in view of the data from recent lung cancer screening trials and the precautionary principle, cardiac CT interpretation in CABG patients should include the assessment of all images by an expert thoracic $\mathrm{CT}$ imager.

\section{Limitations}

Our study involves limited follow-up data. Second, our analysis does not include health care cost evaluation. Finally, since large FOV were used only in sites 2 and 3, prevalence rates could be underestimated for peripheral lung nodules. Strengths of the study involves its multicenter prospective design, as well as the specific prospective definition of the population studied.

\section{Additional files}

Additional file 1. Intra-atrial shunt. A 60-year-old man presenting with a right-to-left intra-atrial shunt (black arrow), as shown by a jet flow of non-enhanced blood in the left atrium (arrow). A 7-mm ostium secundum atrial septal defect with bidirectional flow was also confirmed at transesophageal echocardiography. The patient underwent minimally invasive transcatheter closure with a septal occluder

Additional file 2. Lipomatous metaplasia. A 62-year-old man presenting with lipomatous metaplasia in the lateral wall of the left ventricle, suggestive of myocardial infarction (arrows).

Additional file 3. Pulmonary nodule. 256-slice computed tomography angiography with prospective ECG-gating; 3D volume rendering (A) and axial slice at the level of the left lung apex (lung reconstruction kernel, 5 $\mathrm{mm}$ thickness (B). A, In situ left internal mammary artery with saphenous bridge graft (SVB) to the left anterior descending artery and to a diagonal branch, in a 73-year-old man, with 1-year postoperative follow-up. The LIMA (white arrow) is seen from its origin from the left subclavian artery. The SVB distributes the flow to both the LAD and the diagonal branch. There is also an aortocoronary saphenous vein graft to a distal obtuse marginal branch (black arrow). B, Incidental nodule $(10 \mathrm{~mm})$ in the apex of the left lung (black arrow). Follow-up scans were recommended. The nodule was stable at 12-month follow-up.

Additional file 4. Hepatic lesion. 256-slice computed tomography angiography with prospective ECG-gating; 3D volume rendering (A) and axial slice at the level of the left lobe of the liver (0.8 slice thickness (B). A, In situ left internal mammary artery to the left anterior descending artery, in a 81-year-old man, with 1-year postoperative follow-up. The LIMA (A, white arrow) is seen from its origin from the left subclavian artery. B, Incidental lesion is seen in the 2 nd segment of the left lobe of the liver $(18 \mathrm{~mm})$ (black arrow). Lesion attenuation was 20-25 Hounsfield units, and could be a solid lesion. An ultrasound was recommended.

Additional file 5. Summary of patient characteristics by incidental finding status.

Additional file 6. Comparison of incidental findings studies.

\section{Abbreviations}

CABG: coronary artery bypass graft; CT: computed tomography; IF: incidental findings; FOV: field-of-view.

\section{Authors' contributions}

The manuscript was drafted by IB, JPB and SN, then revised with assistance of CCL. LMS, TMK, AL and NN contributed to the recruitment of patients and data acquisition from local sites. JPB, SN, IB and CCL contributed to the central data collection. JPB, SN and IB contributed to basic statistical analyses and interpretation of data. IB, LMS and CCL performed further statistical analyses and interpretation of data. JPB, SN, IB, GS, AL, NN and CCL contributed to the conception and study design. IB, CCL, TMK, LMS, GS, AL and NN performed critical reviews of intermediate versions of the manuscript. All authors reviewed the manuscript. All authors read and approved the final manuscript.

\section{Author details}

${ }^{1}$ Department of Radiology, Centre Hospitalier de l'Université de Montréal (CHUM), 1051 Sanguinet Street, Montreal, QC H2X OC1, Canada. ${ }^{2}$ Centre de Recherche du Centre Hospitalier de I'Université de Montréal (CRCHUM), Montreal, Canada. ${ }^{3}$ Division of Cardiac Surgery, CHUM, Montreal, Canada. ${ }^{4}$ Division of Cardiac Surgery, Libin Cardiovascular Institute of Alberta, Foothills Medical Centre, University of Calgary, Calgary, Canada. ${ }^{5}$ Division of Cardiac Surgery, McMaster University and Population Health Research Institute, Hamilton, ON, Canada.

\section{Acknowledgements}

Computed tomography technologists and research personnel who contributed in this study.

\section{Competing interests}

The authors declare that they have no competing interests.

\section{Availability of data and materials}

The datasets generated and/or analyzed during the current study are available from the corresponding author on reasonable request.

\section{Consent to publish}

Not applicable.

\section{Ethics approval and consent to participate}

Approval was obtained from the Institutional Review Board of the Centre Hospitalier de I'Université de Montréal, the Institutional Review Board of Hamilton Health Sciences and the Institutional Review Board of the Foothills Medical Centre. Written informed consent obtained from all participants.

\section{Funding}

CCL obtained grants from the Fonds de Recherche Québec Santé (Grants Number 27357 and 29075) and from the Programme de support professoral from the Département de radiologie, radio-oncologie et médecine nucléaire, University of Montreal (Cycle Number 4).

\section{Publisher's Note}

Springer Nature remains neutral with regard to jurisdictional claims in published maps and institutional affiliations.

Received: 20 November 2017 Accepted: 12 January 2018

Published online: 25 January 2018

\section{References}

1. Detre KM, Rosen AD, Bost JE, Cooper ME, Sutton-Tyrrell K, Holubkov R, et al. Contemporary practice of coronary revascularization in US hospitals and hospitals participating in the bypass angioplasty revascularization investigation (BARI). J Am Coll Cardiol. 1996;28(3):609-15.

2. Shroyer AL, Grover FL, Hattler B, Collins JF, McDonald GO, Kozora E, et al. On-pump versus off-pump coronary-artery bypass surgery. New Engl J Med. 2009:361(19):1827-37. 
3. Gramer BM, Diez Martinez P, Chin AS, Sylvestre MP, Larrivee S, Stevens LM, et al. 256-slice CT angiographic evaluation of coronary artery bypass grafts: effect of heart rate, heart rate variability and z-axis location on image quality. PLoS ONE. 2014;9(3):e91861.

4. Desai ND, Pelletier MP, Mallidi HR, Christakis GT, Cohen GN, Fremes SE, et al. Why is off-pump coronary surgery uncommon in Canada? Results of a population-based survey of Canadian heart surgeons. Circulation. 2004;110:117-12.

5. Raja SG, Dreyfus GD. Impact of off-pump coronary artery bypass surgery on graft patency: current best available evidence. J Card Surg. 2007:22(2):165-9.

6. Uva MS, Matias F, Cavaco S, Magalhaes MP. Rationale, design and methodology for a Prospective Randomized Study of graft patency in Off-pump and On-pump Multl-vessel coronary artery bypasS Surgery (PROMISS) using multidetector computed tomography. Trials. 2008;9:44

7. Noiseux N, Stevens L-M, Chartrand-Lefebvre C, Soulez G, Prieto I, Basile F, Mansour S, Dyub AM, Kieser TM, Lamy A, For the CORONARY investigators. Off-pump versus on-pump coronary artery bypass surgery: graft patency assessment with coronary CT angiography: A prospective multicenter randomized controlled pilot study. J Thorac Imaging. 2017:32:370-7.

8. Machaalany J, Yam Y, Ruddy TD, Abraham A, Chen L, Beanlands RS, et al. Potential clinical and economic consequences of noncardiac incidental findings on cardiac computed tomography. J Am Coll Cardiol. 2009;54:1533-41.

9. Flor N, Di Leo G, Squarza SA, Tresoldi S, Rulli E, Cornalba G, et al. Malignant incidental extracardiac findings on cardiac CT: systematic review and meta-analysis. Am J Roentgenol. 2013;201:555-64.

10. Lamy A, Devereaux PJ, Prabhakaran D, Taggart DP, Hu S, Paolasso E, et al. Effects of off-pump and on-pump coronary-artery bypass grafting at 1 year. New Engl J Med. 2013;368:1179-88.

11. MacMahon H, Austin JH, Gamsu G, et al. Guidelines for management of small pulmonary nodules detected on CT scans: a statement from the Fleischner Society. Radiology. 2005;237:395-400.

12. Naidich DP, Bankier AA, MacMahon H, Schaefer-Prokop CM, Pistolesi M, Goo JM, Macchiarini P, Crapo JD, Herold CJ, Austin JH, Travis WD.
Recommendations for the management of subsolid pulmonary nodules detected at CT: a statement from the Fleischner Society. Radiology. 2013;266:304-17.

13. Dewey M, Schnapauff D, Teige F, Hamm B. Noncardiac findings on coronary computed tomography and magnetic resonance imaging. Eur Radiol. 2007;17:2038-43.

14. Cademartiri F, Malagò R, Belgrano M, et al. Spectrum of collateral findings in multislice CT coronary angiography. Radiol Med (Torino). 2007:112:937-48

15. Earls JP. The pros and cons of searching for extracardiac findings at cardiac CT: studies should be reconstructed in the maximum field of view and adequately reviewed to detect pathologic findings. Radiology. 2011:261:342-6.

16. Venkatesh V, You JJ, Landry DJ, Ellins ML, Sheth T. Extracardiac findings in cardiac computed tomographic angiography in patients at low to intermediate risk for coronary artery disease. Can Assoc Radiol J. 2010;61:286-90.

17. Lehman SJ, Abbara S, Cury RC, et al. Significance of cardiac computed tomography incidental findings in acute chest pain. Am J Med. 2009:122:543-9.

18. Henschke Cl, Boffetta P, Gorlova O, Yip R, Delancey JO, Foy M. Assessment of lung-cancer mortality reduction from CT Screening. Lung Cancer. 2011;71:328-32.

19. National Lung Screening Trial Research Team, Aberle DR, Adams AM, Berg CD, Black WC, Clapp JD, Fagerstrom RM, Gareen IF, Gatsonis C, Marcus PM, Sicks JD. Reduced lung-cancer mortality with low-dose computed tomographic screening. N Engl J Med. 2011;365:395-409.

20. Mueller J, Jeudy J, Poston R, White CS. Cardiac CT angiography after coronary bypass surgery: prevalence of incidental findings. Am J Roentgenol. 2007;189:414-9.

21. Koonce J, Schoepf JU, Nguyen SA, Northam MC, Ravenel JG. Extracardiac findings at cardiac CT: experience with 1,764 patients. Eur Radiol. 2009;19:570-6.

\section{Submit your next manuscript to BioMed Central and we will help you at every step:}

- We accept pre-submission inquiries

- Our selector tool helps you to find the most relevant journal

- We provide round the clock customer support

- Convenient online submission

- Thorough peer review

- Inclusion in PubMed and all major indexing services

- Maximum visibility for your research

Submit your manuscript at www.biomedcentral com/submit 